\title{
RELIGIÃO E PARENTESCO \\ ENTRE OS BAKONGO DE LUANDA
}

Luena Nunes Pereira*

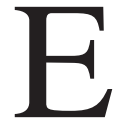

ste texto busca sintetizar um dos argumentos da minha tese de doutorado centrada na recomposição social e étnica do grupo bakongo residente em Luanda. ${ }^{1}$ Ali procurei discutir as formas específicas pelas quais os bakongo em Luanda dão conta de se reorganizar enquanto grupo, considerando suas clivagens e diferenças internas, numa resposta estruturada a processos de transformação. Defendi que esta rearticulação interna dos bakongo permitiu-lhes reivindicar o direito ao reconhecimento de um lugar legítimo na sociedade mais ampla de Luanda e de Angola.

Nesta rearticulação, o campo religioso se apresentou como a instância capaz de mediar e integrar diferentes esferas (do parentesco, do político e do identitário), dando sentido tanto às transformações ocorridas como também aos processos de continuidade, entendendo que estruturas e instituições precisam ser constantemente recriadas e construídas para que possam fazer e produzir sentido.

Procuro questionar a ideia de que as igrejas, notadamente as pentecostais, teriam ocupado o espaço deixado por um parentesco supostamente enfraquecido pelos processos de modernização (migração, urbanização, economia de mercado etc.). Meu argumento tem sido o de que

Professora Adjunta da Universidade Federal Rural do Rio de Janeiro. luenapereira @ yahoo.com.br 1 Luena Pereira, "Os Bakongo de Angola: religião, política e parentesco num bairro de Luanda" (Tese de Doutorado, Universidade de São Paulo, 2004). 
as igrejas têm, no espaço urbano e multiétnico da capital, um lugar concorrente, mas ao mesmo tempo complementar às organizações baseadas no parentesco. Mais do que disputa ou colaboração, as organizações religiosas participam, de formas diferentes, da própria reconfiguração deste parentesco, bem como da rearticulação de narrativas étnicas e nacionais.

Assim, procuro relativizar certos supostos analíticos quanto às transformações recentes ocorridas em Angola, particularmente agravadas pela guerra prolongada, tais como a urbanização acelerada, o espalhamento da lógica capitalista e ampliação do contraste social, bem como os processos de globalização. Estas mudanças, em geral, são vistas pelo prisma da "perda" e da "ocidentalização". No caso angolano, a chamada "ocidentalização" tem sido sinalizada pela perda de competência no manejo das línguas maternas e pela disseminação do português. Neste contexto, os processos de afirmação identitária são percebidos pelo viés da manipulação étnica, esvaziadas de seus "conteúdos" culturais supostamente "autênticos" que seriam as formas de organização baseadas no parentesco, línguas maternas, no modo de vida rural etc.

A presença das igrejas pentecostais no campo religioso angolano - e africano - é interpretada como uma radicalização destes processos de mudança cultural, isso fica claro na "demonização" da religiosidade local e pelo ataque à eficácia e à legitimidade dos sistemas tradicionais de culto e cura, bem como pelo distanciamento dos grupos de parentesco, rompendo sua legitimidade em prol da comunidade de fiéis.

Minha intenção é rever a percepção que alinha urbanização à perda cultural, chamando atenção para a continuidade dos aspectos considerados "tradicionais", como as organizações baseadas no parentesco, o uso de línguas maternas em diversos contextos, especialmente os rituais, e as formas múltiplas de sociabilidade no espaço urbano como modos de articular transformação e permanência. Procuro demonstrar esta articulação através da análise do campo religioso e da multiplicação de igrejas, especialmente com a expansão pentecostal, e sua imbricação com as organizações de parentesco, no caso dos bakongo.

Os bakongo, terceiro maior grupo étnico de Angola, localizam-se na parte norte do território, e estão presentes também na República 
Democrática do Congo e no Congo Brazzaville. Nesta região emergiu o antigo Reino do Kongo, formado provavelmente no século XIV, com o qual os portugueses estabeleceram seus primeiros contatos na costa ocidental da África Austral, em fins do século XV.

Trato aqui dos bakongo que vivem na capital de Angola, Luanda, estimados meio milhão de pessoas em uma cidade de quatro milhões de habitantes (2001). Formam um grupo extremamente variado, com diferenças marcantes de classe social e de origem regional. A diversidade interna ao grupo é marcada pela experiência de exílio de parte deste contingente na República Democrática do Congo entre as décadas de 1950 e 1970. Parte deste grupo retornou a Angola após a independência, em 1975, instalando-se boa parte em Luanda. É principalmente entre esses ex-exilados, chamados por vezes de "regressados", que tenho realizado minhas pesquisas.

A maioria dos ex-exilados bakongo que voltou para Angola nas décadas posteriores à independência dedicou-se ao comércio varejista, tendo sido responsável pela organização do mercado paralelo da cidade de Luanda, no contexto de um regime de cunho socialista. A secular tradição comercial de alguns setores desse grupo, somada à experiência de comércio desenvolvida no Congo durante os anos de exílio, concorreu para a montagem e articulação de redes mercantis de longa distância. As redes de comércio puseram em evidência as relações dos grupos residentes na capital com seus parentes estabelecidos nas províncias do norte do país e no outro lado da fronteira. Com a liberalização econômica, na década de 1990, o mercado paralelo disseminou-se mais ainda, transformando-se no setor informal da economia. A partir de então, os regressados ficaram relegados a um papel menos proeminente.

Meu trabalho de campo foi realizado entre 1998 e 2001 em Luanda, mais especialmente, no bairro do Palanca, na periferia da capital. O bairro, na época, tinha cerca de setenta mil pessoas e era habitado majoritariamente pelo contingente bakongo. Levei também em consideração as relações de parentesco e de afinidade que se estendem por toda a cidade, unindo inclusive setores de classe, origem e trajetórias diferenciadas. 


\section{Política e religião: o cristianismo e os movimentos religiosos na área kongo}

Não se pode compreender o fenômeno pentecostal em Angola fora de dois processos. O primeiro, da disseminação mais ampla do pentecostalismo no mundo cristão, desde os anos 1980. Na África esta expansão está indissociavelmente ligada aos movimentos messiânicos emergidos no período colonial, e à criação das igrejas africanas após as independências. $^{2}$

O segundo processo remete à própria história angolana. Estamos nos referindo à antiga presença missionária no Reino do Kongo. A cristianização desta região foi interpretada de várias formas por diversos autores. ${ }^{3}$ Vários destes concordam que sistemas culturais e religiosos se combinam mais do que se sucedem e só podem ser compreendidos com o olhar voltado para os processos políticos e a luta por controle de pessoas, símbolos e significados. Na sociedade kongo, a religião foi desde muito tempo a principal instância de organização política e social. Isto tem fundamento na estrutura tradicional kongo onde, tal como em outras sociedades, os chefes exerciam seu poder político legitimados por um poder sagrado conferido ritualmente. A linguagem do poder remete, assim, ao sagrado, à capacidade de manipulação, pelos chefes e sacerdotes, de forças poderosas advindas do outro mundo (ancestrais e outras divindades).

Os contatos com os portugueses, a partir de fins do século $\mathrm{XV}$, introduziram o cristianismo, adotado rapidamente pela elite real congolesa. A cristianização representou, naquele momento, uma estratégia de concentração do poder real para fins de reorganização política do Reino

2 Sobre movimentos religiosos africanos, ver: James Fernandez, "African Religious Movements", Annual Review of Anthropology, n. 7 (1978), pp. 195-234. Sobre pentecostalismo em África, Birgit Meyer, "Christianity in Africa: From African Independent to Pentecostal-Carismatic Churches", Annual Review Anthropology, n. 33 (2004), pp. 447-74.

3 Georges Balandier, Sociologie actuelle de l'Afrique noire, Paris: PUF, 1963 [1955]; John Thornton, The Kongolese Saint Anthony: Dona Beatriz Kimpa Vita and the Antonian Movement, 1684-1706, Cambridge: Cambridge University Press, 1998; António Gonçalves, Le lignage contre l'Etat: dinamique politique Kongo du XVIéme au XVIIIéme siécle, Évora: Universidade de Évora, IICT, 1985; Wyatt MacGaffey, Religion and Society in Central Africa, Chicago: The University of Chicago Press, 1986. 
do Kongo. Esta interpretação é demonstrada pelo batismo do rei e das famílias mais importantes do reino e não facultado, de início, à população comum.

A participação do cristianismo, e de seus agentes europeus, no desenvolvimento político do Reino do Kongo encontrou seu momento crítico no movimento Antoniano, no início do século XVIII. Tratou-se de um movimento religioso, chamado também messiânico, que buscava a restauração do Reino do Kongo, dilacerado pelas guerras civis que se sucederam após a Batalha de Ambuíla (1665), quando uma nova relação, de vencedor e vencido, se estabeleceu entre o Reino do Kongo e os portugueses. A reação religiosa procurou assim recuperar o protagonismo político perdido, retraduzindo o cristianismo nos termos de uma lógica local, afastando-o do controle dos missionários europeus. ${ }^{4}$

Desde o final do século XIX, o processo de recristianização da região do Kongo com a implantação de missões católicas e protestantes, já sob o domínio colonial, assistiu vários movimentos religiosos, sendo o mais importante deles o Kimbanguismo, na década de 1920, no Congo Belga.

A articulação entre política e religião foi a chave de leitura de todos os autores debruçados sobre estes movimentos religiosos ao longo do século XX. ${ }^{5}$ Os movimentos chamados messiânicos ou proféticos, numerosos na região kongo, estavam relacionados à busca popular por autonomia simbólica e política, costurando concepções locais de poder e sagrado junto à linguagem universalista do cristianismo e a mobilização coletiva na tentativa de recomposição do sistema social, drasticamente transformado pela colonização. Não cabe aqui um aprofundamento da análise destes fenômenos, discutidos por uma vasta literatura, mas apenas chamar atenção para a continuidade, no campo religioso africano, dos movimentos religiosos do século XX e a dissemina-

\footnotetext{
4 Thornton, The Kongolese Saint Anthony.

5 Balandier, Sociologie actuelle; António Gonçalves, "Analyse sociologique du Tokoisme en Angola", Anthropos, n. 79 (1984), pp. 473-83; Martial Sinda, Le messianisme congolais et ses incidences politiques: kimbanguisme, matsouanisme, autres mouvements, Paris: Payot, 1972; Alfredo Margarido, "The Tokoist Church and Portuguese Colonialism in Angola", in Ronald Chilcote (org.), Protest and Resistance in Angola and Brazil (Califórnia: University of Califórnia Press, 1972).
} 
ção das igrejas independentes africanas. Estas igrejas são maioria entre as do espectro pentecostal em expansão em muitos países da África, inclusive Angola, onde a proeminência da atividade religiosa entre os bakongo é notável.

$\mathrm{O}$ quadro esboçado sugere uma série de questões que encontram pistas na peculiaridade da região kongo com as vicissitudes da colonização que dividiu seu território. Podemos encontrar também algumas respostas na sua complexa história, na qual não apenas a longa presença missionária cristã parece ter tido um papel determinante, mas também na forma como o cristianismo encontrou dentro da cosmologia e do sistema religioso kongo espaços de correlação. Retemos deste breve histórico tanto a importância da instância religiosa na estruturação do poder tradicional bakongo, como a centralidade da religião cristã no processo de transformação da sociedade kongo decorrente da sua relação com o poder e a cultura europeias.

Percebemos no campo religioso angolano, desde a década de 1990, uma diversificação crescente do espectro de igrejas e confissões. Esta diversificação é marcada, principalmente, pela disseminação das igrejas pentecostais e igrejas de cunho profético, chamadas "sincréticas" ou igrejas independentes africanas, geralmente de matriz cristã. Apesar da proliferação destas igrejas ser um fenômeno marcante no mundo cristão, no caso angolano esse fenômeno assume um perfil marcadamente bakongo. Ou seja, os bakongo não são, entre as lideranças religiosas, os únicos protagonistas, mas são, com certeza, os mais numerosos e proeminentes. Haveria alguma relação entre este dinamismo religioso e a recorrente reivindicação política e identitária que, neste grupo, assume uma linguagem propriamente religiosa?

O contexto da atual, Angola independente, ainda que viva um conturbado processo de construção nacional, não pode ser de forma ligeira equiparada ao período colonial ou da desestruturação do Reino do Kongo, momentos históricos de emergência de movimentos messiânicos contestatórios. Embora não se coloque mais a ruptura com a dominação colonial, permanece a busca de um espaço político que implique num reconhecimento da especificidade bakongo e do seu lugar na nação angolana. Nesse sentido, trata-se de entender, no período pós- 
independência, a articulação bakongo na sociedade angolana mais ampla, já constituída como nação, e com as instituições de Estado.

Tentando compreender o lugar ocupado hoje pelos bakongo na sociedade angolana, mas considerando também a complexidade interna deste grupo na capital do país - lugar privilegiado para observação - a dinâmica religiosa dos bakongo aparece como uma dimensão fundamental para pensar a articulação que estes fazem entre si, enquanto grupo, e com a sociedade nacional. Percebe-se assim que a instituição religiosa vem permitindo ao grupo recompor seu passado e seu presente, sua forma especial de associar processos de continuidade cultural e mudanças, dando-lhes significados adequados ao seu contexto atual e a uma história marcada pela migração e pelos deslocamentos. Investigar a dimensão religiosa entre os bakongo pode permitir desvendar uma forma particular pela qual é possível processar as rupturas entre os períodos colonial e pós-colonial e as vivências experimentadas em espaços nacionais distintos. A religião institucionalmente organizada através das igrejas cristãs sendo o cristianismo a religião majoritária em Angola - pode ser vista como o elo que liga estas instâncias: passado e presente, sociedade nacional e grupo étnico, construção de identidades internas ao grupo e para fora deste. A proliferação de igrejas, no caso dos bakongo, pode demonstrar uma atualização, para o contexto nacional angolano, de uma tradição de contestação política e a busca de afirmação identitária, tendo-se em consideração um ambiente político restritivo.

Cabe considerar que entendemos que a articulação político-identitária associada à expressão e às instituições religiosas tem sido uma forma regular da organização de importantes setores bakongo. A religião assim não se configura numa mera "válvula de escape" dentro de um ambiente político restrito, como alguns autores interpretaram, ou seja, uma forma de organização possível à espera de instituições "modernas", como partidos políticos ou organizações formais. Entretanto, cabe observar que na história kongo há uma reiterada relação entre emergência de movimentos religiosos e um contexto de perda de autonomia política e crise institucional.

Do ponto de vista interno aos bakongo, a religião parece ser o idioma de rearticulação do grupo, que vem sofrendo um processo im- 
portante de transformação social, especialmente de parte de suas referências tradicionais, pela urbanização acelerada. Assiste-se uma reordenação destas instituições tradicionais, tendo em vista sua inserção na sociedade nacional.

Instituições tradicionais remetem principalmente àquelas baseadas no parentesco que, no caso bakongo, estão ancoradas numa complexa interação entre a sucessão matrilinear e a patrilateralidade, esta última relacionada à expansão territorial do grupo e à função sagrada. A tendência à sucessão paterna, através da influência ocidental, fortemente absorvida pelas sociedades colonizadas, vem aumentando uma tensão nas sociedades cuja transmissão de herança, de status e de poder político se dá pela linha materna. Essa tendência, bem como uma percepção da diminuição da importância dos laços de parentesco na sociedade "moderna" e urbanizada (onde não se coloca mais o direito sobre a terra) vem gerando a necessidade de recomposição de novas e antigas instituições e produção de lideranças que, entre os bakongo, vem sendo levado a cabo, entre outras formas, pela instância religiosa, como pretendo demonstrar.

\section{O parentesco entre os bakongo de Luanda}

O fundamento da estrutura social kongo, a organização baseada no "clã", o conjunto de matrilinhagens, é uma característica que não se alterou na sua base, embora tenha sofrido certas mudanças, se considerarmos o contexto urbano na qual se insere boa parte da população bakongo de Angola.

Toda a literatura que descreveu a vida social kongo, tanto a etnológica como a missionária (esta produzida desde os sécs. XVI e XVII), refere-se a essa organização de parentesco. ${ }^{6} \mathrm{O}$ fundamento do parentes-

6 Baseei-me, para a caracterização do parentesco e do sistema social kongo, principalmente em Balandier, Sociologie actuelle; e Wyatt MacGaffey, Custom and Government in the Lower Congo, Berkeley/Londres: University of California Press, 1970; MacGaffey, Religion and Society; António Gonçalves, Reestruturação do poder político e inovação social na sociedade Kongo, Évora: Instituto Superior Econômico e Social de Évora, 1984; Gonçalves, Le lignage contre l'Etat. Para o sistema social encontrado no Reino do Kongo, William Randles, L'ancien royaume du Congo: des origines à la fin du XIXe siècle, Paris: EHESS, 2002 [1968]; John Thornton, The Kingdom of Kongo. Civil war and transition, 1641-1718, Wisconsin: The University of Wisconsin Press, 1983; e Georges Balandier, La vie quotidienne au royaume de Kongo: du XVI au XVIII siècle. Paris: Hachette, 1965. 
co kongo reside na Kanda (ou Nkanda). A Kanda é o grupo de parentesco organizado em linha materna, descendente de uma antepassada comum. A kanda define o grupo exógamo. Empiricamente, a Kanda costuma estar associada ao "clã" ( $m$ vila), embora aquela faça mais referência ao grupo local do que o clã, que remete à categoria de descendência mais ampla e não implique em exogamia. ${ }^{7}$ A Kanda se divide em linhagens, ou "barriga" (vumu), ou seja, o grupo de descendência até a quarta geração que regula os direitos de herança. A Kanda, que por sua própria definição abrange os vivos e seus antepassados, estabelece duas categorias fundamentais de pessoa entre os bakongo: os indivíduos de livre direito, que são aqueles pertencentes a uma dada linhagem materna, com todos os direitos relativos a sucessão e herança, e os outros, estrangeiros ou escravos que, não possuindo Kanda e incapazes de declarar sua mvila (genealogia), têm um lugar subordinado na estrutura social.

A colonização, o deslocamento de populações e o processo de urbanização, ainda que diferenciado nos três espaços coloniais (expressiva nos dois Congos, mas débil em Angola), implicaram na perda de poder político e no enfraquecimento da sucessão e da herança da posse da terra. ${ }^{8}$ A urbanização, de modo mais definitivo, fez cessar totalmente o exercício do poder das chefias sobre a terra e sua alocação. Não é outro o motivo para ausência de referência, em Luanda, a uma categoria importante, intermediária entre a Kanda e a linhagem, que são as casas $(n z o)$, que dividem a Kanda em três seções e regulam o acesso a terra. Esta referência é encontrada na bibliografia que trata da organização social kongo dos séculos passados e no meio rural mais recente. ${ }^{9}$ No espaço urbano, não só não se coloca mais o direito a terra, como a distribuição residencial é submetida a outras circunstâncias. Todavia, percebemos uma continuidade do sistema virilocal (a mulher se desloca para viver junto ao marido).

Atualmente, as estruturas da matrilinhagem têm a função, basicamente, de regular os casamentos dentro do grupo (fora da Kanda), de definir o grupo de herança, bem como de estabelecer a autoridade dentro

\footnotetext{
Macgaffey, Religion and Society, p 18.

Macgaffey, Custom and Government; e Balandier, La vie quotidienne.

Ver nota 6.
} 
da família, perdurando o sistema de chefia familiar centrada na figura do tio materno ou tio-avô materno, o membro mais velho da Kanda (nkazi).

Embora o nome da sua própria Kanda seja, em geral, de conhecimento de cada mukongo (indivíduo do grupo bakongo), não são todos os que detêm o conhecimento de toda a tradição que se expressa, entre outras coisas, na declamação da mvila, a genealogia do clã, que remonta a várias gerações. O conhecimento e a reprodução desta tradição permitem a circulação de poder e prestígio entre as diversas lideranças familiares, reforçando a disputa deste mesmo prestígio e, ao mesmo tempo, os laços de identificação do grupo como um todo. Deste modo, a identificação da Kanda também tem sido um instrumento de reconhecimento e exercício do reforço da identidade étnica para dentro do grupo.

A transformação considerada mais notável na estrutura de parentesco kongo, mencionada por vários mais velhos, seria aquela ocasionada pela tendência à valorização do poder do pai em detrimento do poder do tio materno. Este processo indica se não uma transição do sistema matrilinear para patrilinear, uma forte influência desta última nas formas de organização familiar, o que também implica na nuclearização da família em detrimento da chamada "família extensa". Esta transformação é atribuída à ocidentalização, seja pela influência da missionação, seja pela imposição do direito ocidental advindo com a colonização e depois.

Embora sem desprezar estes fatores de transformação, cabe lembrar que o lado paterno nas sociedades kongo sempre desempenhou um papel importante, como no acesso a terra e na sucessão de títulos políticos e espirituais. Entretanto, no enquadramento urbano, o poder do pai teria aumentado ainda mais, tendo em vista a proeminência da família nuclear, a mudança evidente do sistema econômico, que alterou as formas de produção e distribuição de riqueza e o aumento da fragmentação dos grupos de parentesco, sobretudo na distribuição residencial.

A dualidade entre a influência das famílias materna e paterna que se reproduz nas situações de casamento tradicional, quando se divide os bens recebidos pela família do noivo entre a família do pai e a família materna da noiva, parece indicar, todavia, que esta tensão não é tão recente, estando inscrita no sistema kongo. 


\section{Relação pai filho (tata-mwana) e a importância do pai}

A dificuldade na compreensão dos sistemas de parentesco e do sistema político decorrente ou relativamente divergente desta estrutura esbarra na própria definição de um sistema como matrilinear, patrilinear ou misto (dupla descendência) e da notável variação entre diversos sistemas empíricos diante da mesma definição antropológica. ${ }^{10}$

A categorização da sociedade kongo como matrilinear, a partir da definição de linhagem e sucessão por via materna, da concepção nativa de tradição e da declaração da mvila para definir e defender direitos de herança, ocasionou certa rigidez na definição do sistema. Disto decorreu a interpretação das variações e transformações observadas no sistema empírico como mudanças introduzidas a partir da cristianização, da colonização ou da urbanização e não como variações resultantes da própria tensão e das contradições inerentes ao sistema a um só tempo matrilinear e virilocal. O sistema segmentar kongo baseia-se nestas contradições para fazer interferências constantes e construir justificações ideológicas que objetivam mudanças e lutas por espaço político, territorial e de autoridade de grupos colocados em posições de inferioridade por conta da primazia da primogenitura e da antiguidade, que opõem irmãos e linhagens mais velhas e/ou mais antigas a irmãos mais novos e linhagens mais recentes.

Wyatt MacGaffey e António Gonçalves dão claras indicações da proeminência do papel tradicional do pai e da patrilinhagem na transmissão ao filho (classificatório) do direito a terra, uma transmissão de poder político. ${ }^{11} \mathrm{O}$ exercício do poder sobre a terra implica num pacto com os antepassados, donos da terra, lhe permitindo sua fertilidade e produtividade e dando viabilidade ao grupo postulante. A doação da terra é assim uma relação de pai para filho, efetivando uma doação a um só tempo política e sagrada. O doador tem estatuto de pai (tata) e é como filho (mwana) que o novo chefe político assume o comando do

10 Audrey Richards, "Alguns tipos de estrutura familiar entre os bantos do centro", in RadcliffeBrown e Daryl Forde, Sistemas políticos africanos de parentesco e casamento [African Systems of Kinship and Marriage] (Lisboa: Fundação Calouste Gulbenkian, 1982 [1950]).

11 MacGaffey, Custom and Government; e Gonçalves, Le lignage contre l'Etat. 
novo território e deve deferência ao seu doador. Esta relação de doação permite ao filho, exercendo seu poder sobre um novo domínio, constituir uma nova (matri)linhagem. ${ }^{12}$

O acesso a terra através do pai é um recurso principalmente do filho ou linhagem mais jovem ou mais recente, já que à primogenitura é facultada a terra da matrilinhagem (o sobrinho mais velho herda do tio materno). Sendo assim a relação tata - mwana regula as fragmentações inerentes à linhagem, ou seja, as cisões de linhagens menores que saem à procura de novas terras e de homens em busca de exercerem chefia. ${ }^{13}$

A relação entre pai e filho é, portanto, a relação de aliança política propriamente dita, que garante a legitimação das linhagens menores ou mais novas que querem autonomizar-se. Dá ao pai a possibilidade de produzir uma clientela que compensa sua situação desfavorável, de procriar para benefício de outro (o irmão da esposa), como também de contrabalançar a pressão por poder dentro da sua linhagem, vindo dos seus próprios sobrinhos. A estrutura segmentar, fragmentada, da organização social kongo é assim equilibrada pelo papel legitimador do pai, que confere a esta fragmentação uma linguagem de parentesco, impedindo a atomização dos grupos kongo, garantindo a unidade, uma identidade e o recurso comum (através da tradição) para resolução de litígios sobre a terra e o poder.

Portanto, a relação pai-filho é uma relação de senioridade e de transferência de autoridade espiritual. ${ }^{14} \mathrm{O}$ filho recebe do pai as insígnias para governar. Está inscrita nos mitos a passagem da autoridade espiritual de pai para filho, mesmo quando este é o filho primogênito que herda do tio a chefia da matrilinhagem. ${ }^{15}$

${ }_{12}$ Gonçalves, Reestruturação do poder político, p 11.

13 Segundo Gonçalves, Reestruturação do poder político, p. 47, o casamento do filho com a prima cruzada patrilateral efetiva a aliança entre pai e filho, assegurando o poder do filho sobre seu novo domínio.

14 MacGaffey, Custom and Government, p 55.

15 As relações de proximidade com o pai incluem a proteção contra a feitiçaria, que é a forma pela qual se expressam as relações de disputa entre tios e sobrinhos no sistema matrilinear. Sobre a complementariedade da linhagem secundária (paterna) em sociedades matrilineares e sua função espiritual, ver Victor Turner, O processo ritual: estrutura e anti-estrutura, Petrópolis: Vozes, 1974, pp. 16-159. 
Esta relação espiritual encontrou uma homologia na cosmologia cristã, na qual a autoridade sagrada é também uma herança de pai para filho (expressa pela Santíssima Trindade). Ela nos possibilita demonstrar a hipótese de que a relação espiritual e territorial entre pai e filho se reporia na organização das igrejas pentecostais e proféticas e na estrutura segmentar da proliferação destas igrejas, tal como sugere MacGaffey para o caso observado na RDC.

\section{Os bakongo e as igrejas}

Segundo o INAR (Instituto Nacional para Assuntos Religiosos, órgão do governo que regula e registra as instituições religiosas), as igrejas se multiplicam por toda a cidade de Luanda, do centro à periferia. Mas, em bairros cuja maior parte da população é originária do norte de Angola é observado um número maior de igrejas e de diferentes denominações.

Entre intelectuais angolanos, principalmente escritores ficcionistas, jornalistas e alguns pesquisadores, a proliferação das igrejas é percebida como um equivalente da candonga, uma espécie de "candonga espiritual". ${ }^{16}$ Candonga refere-se ao comércio paralelo, hoje informal, alastrado pelo país, alimentado pelo contrabando e pelas práticas tácitas ou informais de trocas e da comercialização do favor, da pequena e disseminada corrupção. Esta percepção alia-se a noção corrente de pastores inescrupulosos que enganam fiéis desesperados em busca de cura para suas doenças e aflições e de que a expansão e proliferação das igrejas é decorrência direta da crise econômica e da pauperização da população. A abertura de igrejas seria, nessa chave, um expediente para o enriquecimento ilícito, prática análoga à corrupção, ao favorecimento, ao contrabando, ao comércio ilegal etc. A clientela da igreja cresceria assim a braços com o aumento da pobreza e do desespero, com a retirada do Estado do atendimento à população e com o crescimento desordenado das cidades.

${ }^{16}$ Christine Messiant, "Angola, les voies de l'ethnisation et de la décomposition. II - Transition à la démocratie ou marche à la guerre? L'épanouissement des deux "Partis armés" (Mai 1991-Septembre 1992)", Lusotopie - Transitions libérales en Afrique Lusophone (1995), pp. 181-220. 
A "tese da candonga espiritual" casa-se facilmente com o histórico dos bakongo, enquanto grupo que introduziu a prática do comércio informal/ilegal logo após a independência de Angola. Reproduz-se desse modo, o mesmo estereótipo do mukongo/regressado voltado para as práticas ilegais de comércio (práticas depois seguidas por toda a população), aquele que teria tido a "iniciativa" de "enriquecer" indevidamente com o "desespero" alheio, através da abertura de igrejas e cobranças de dízimos.

Outra forma muito comum de analisar o fenômeno da proliferação de igrejas em Angola e em África é relacioná-la ao declínio da solidariedade familiar. Esta hipótese vê

o crescimento das igrejas protestantes e pentecostais [...] como uma resposta à necessidade dos agentes sociais de construírem redes de solidariedade e de se agarrarem a valores novos para enfrentar a desintegração ocasionada pela guerra civil

como aponta Peter Fry em um artigo sobre a expansão das igrejas pentecostais no Moçambique do pós-guerra. ${ }^{17}$ A situação de guerra ou pósguerra que provocou o deslocamento de populações para os centros urbanos teria gerado uma situação de perda de referências e laços que seriam reconstruídos pela adesão à igreja, uma instituição tão englobante e totalizadora como as sociedades de parentesco. Esta interpretação, entretanto, não logra explicar como e porque esta "forma muito específica de sociabilidade"18 substitui - se é que substitui - formas mais antigas e também eficazes de sociabilidade. O autor duvida que tenha havido uma sucessão dos laços religiosos sobre os familiares. A hipótese é que eles tenham sido somados, e de formas variadas.

Da mesma forma que os bakongo não são os mais pauperizados no contexto da crise social em Luanda, tampouco seus laços familiares encontram-se, de modo geral, esgarçados. Os bakongo são notórios por serem muito persistentes em termos de manutenção e revitalização de

17 Peter Fry, "O Espírito Santo contra o feitiço e os espíritos revoltados: 'civilização' e 'tradição' em Moçambique", Mana, v. 6, n. 2 (2000), pp. 65-95.

${ }^{18}$ Fry, "O Espírito Santo contra o feitiço", p. 82. 
laços familiares, de coesão interna e de apego às tradições. Foi a partir desta constatação que iniciei meu conjunto de indagações sobre as relações entre igreja e família no grupo bakongo em Luanda. Como se relacionaria a adesão às diversas igrejas e os laços familiares entre os bakongo? As adesões religiosas seguem os já existentes laços de parentesco ou desafiam estes laços? Qual o papel das relações de vizinhança na adesão religiosa e no trânsito entre igrejas? Haveria alguma conexão entre a estrutura social e de parentesco dos bakongo e a proliferação das igrejas, bem como as cisões e desmembramentos dentro delas?

Os próprios bakongo buscam formular explicações de diversas ordens sobre o fato de a proliferação de igrejas ser um fenômeno associado principalmente a este grupo, notadamente entre os regressados. A primeira explicação diz que os bakongo são os mais religiosos entre os angolanos, são cristãos há muito mais tempo e, portanto, são naturalmente inclinados à vida religiosa e a frequentar igrejas. Já a diversidade de igrejas, segundo alguns deles, estaria relacionada ao fato dos "bakongo gostarem de mandar", referindo-se à estrutura segmentar da sociedade kongo, na qual chefes de linhagens menores buscam novos espaços para a criação (e a liderança) de novos grupos. Esta estrutura se reproduziria no contexto atual através das cisões e desmembramentos entre as igrejas, nas quais emergem novas lideranças que comandam grupos menores e autônomos numa organização de menor hierarquia. Vamos voltar a este ponto mais adiante.

Uma constatação muito presente é a influência do Congo/Zaire e a presença de "zairenses" na criação de múltiplas igrejas e dissidências de igrejas. Muitas vezes, os bakongo de Luanda recusam a apreciação de que são angolanos do norte os responsáveis pelo grande número de igrejas. Dizem que são os imigrantes congoleses, e não os regressados, os que trazem as igrejas do Congo a Angola, ou que a proliferação de igrejas está disseminada por todo o território angolano, não sendo só "coisa dos bakongo". ${ }^{19}$

19 O Congo/Zaire, desde a história colonial, foi utilizado como bode expiatório para certos fenômenos ocorridos em Angola, como a contestação nacionalista, apontada pelos colonos portugueses como uma ação provocada exclusivamente do exterior, alimentada pelo pânico que o conturbado processo de independência do Congo causou entre os colonizadores. Depois, os regressados do 
Outros, por sua vez, num sentido ao mesmo tempo de autocrítica e de autoindulgência, afirmam que sendo os bakongo inclinados ao comércio e muito mais viajados que os outros angolanos são capazes de ver mais longe e de farejar um "bom negócio". Assim, apenas teriam feito mais cedo o que os outros angolanos só vieram a realizar anos depois: tanto a montagem do comércio informal como a abertura de igrejas (e de partidos políticos e de organizações não-governamentais) foram iniciativas tomadas, primeiro, pelos angolanos do norte, práticas depois "copiadas" pelos outros angolanos.

Juntando informações fornecidas pelos próprios fiéis e alguns dados obtidos informalmente no INAR e em Viegas, ${ }^{20}$ comecei por mapear as igrejas de maior adesão entre os bakongo, explorando a composição de sua audiência e as formas pelas quais os fiéis aderem às diferentes igrejas. Mesmo não sendo possível a percepção de um padrão claro, vamos procurar, mais adiante, entender os meios pelos quais se processam os desmembramentos e cisões entre as igrejas, para além da suposta vaidade e ganância de seus dirigentes.

A Igreja Católica, tal como em todo o país, é a que tem mais adeptos entre os bakongo. A Igreja Batista, a principal igreja protestante implantada no norte de Angola, segue como outra igreja de grande inserção - e autoridade - entre esta população, ainda que se divida em diversas denominações. Dentre estas, a Igreja Evangélica Batista em Angola (IEBA), a herdeira da antiga Baptist Missionary Society (BMS) do tempo colonial, continua tendo mais adeptos, ${ }^{21}$ talvez um pouco mais do que a Igreja Kimbanguista (Igreja de Nosso Senhor Jesus Cristo sobre a Terra pelo Profeta Simão Kimbangu), a principal igreja africana dos bakongo de Angola e do Congo também do período colonial. Ou-

Congo teriam introduzido em Angola a desordem da economia informal e hoje a "desordem religiosa". Esta acusação aos congoleses é feita pelos angolanos, inclusive os de origem bakongo, que absorveram parte dos estereótipos que lhes são atribuídos. Ver Luena Pereira, "Os regressados na cidade de Luanda: um estudo sobre identidade étnica e nacional em Angola" (Dissertação de Mestrado, Universidade de São Paulo, 1999).

${ }^{20}$ Fátima Viegas, Angola e as religiões, Luanda: Do autor, 1999.

21 Sobre a Igreja Batista em Angola, James Grenfell, História da Igreja Batista em Angola (1879-1975), Lisboa: BMS, 1998. Sobre a história das igrejas em Angola, Lawrence Henderson, A igreja em Angola: um rio com muitas correntes, Lisboa: Editorial Além-Mar, 1990. 
tras igrejas de referência entre a população bakongo, desde o período colonial e com forte presença em Luanda são a Igreja Exército da Salvação e a Igreja Tocoísta (Igreja do Nosso Senhor Jesus Cristo no Mundo). ${ }^{22}$ A tradição familiar parece conservar-se assim como o principal critério de adesão dos bakongo às igrejas, reproduzindo, dentro das famílias, ao longo das décadas, os adeptos das principais igrejas.

As igrejas pentecostais e proféticas, ${ }^{23}$ em geral, vão colhendo fiéis destas igrejas citadas acima, a princípio entre os mais jovens e mulheres. Mas, com poucas exceções, não parecem ter uma adesão numerosa, nem de base familiar. Isso nota-se pela composição da audiência que acorre às igrejas aos domingos. Nas principais igrejas de origem missionária ou herdeiras dos movimentos messiânicos relacionadas acima, vê-se grupos familiares presentes, enquanto que as igrejas mais recentes, pentecostais e proféticas, são procuradas mais por mulheres e jovens e menos por homens. Nota-se também presença bem menor de crianças nos cultos pentecostais em comparação às igrejas mais antigas.

\section{Aspectos de identidade e cultura nos cultos religiosos}

Há outros aspectos a destacar sobre as igrejas, não somente quanto à composição etária, de gênero ou socioeconômica. Alguns sinais indicam, por exemplo, um maior ou menor envolvimento de cada igreja com certas instituições bakongo, dando evidências de situações de aproximação e/ou ruptura que cada comunidade da igreja estabelece com instituições da esfera familiar. Estes aspectos sinalizam também uma postura identitária de cada grupo religioso em relação à sociedade mais ampla, seja nacional, seja de Luanda, seus símbolos e valores. São eles:

22 A Igreja Tocoísta foi criada pelo profeta Simão Toco, mukongo angolano emigrado no Congo. A igreja se tornou, ao longo do período colonial e depois, uma igreja de âmbito nacional.

23 A distinção entre igrejas pentecostais e proféticas (também chamadas africanas ou mpeve (y)a longo, termo kikongo para Espírito Santo) atende a um critério de origem destas igrejas. Igreja profética ou africana seria uma designação genérica para igrejas de origem africana (algumas herdeiras dos chamados movimentos messiânicos ocorridos no período colonial), e pentecostal seriam aquelas vindas da Europa ou da América. Quanto às práticas adotadas, tais como rituais de cura, eventos de glossolalia e exorcismo, encontramos entre elas mais semelhanças que distinções. 
o uso das línguas nos cultos (português, kikongo, ${ }^{24}$ lingala ${ }^{25}$ e outras), o tipo de cânticos, o uso ou não de roupas de estilo africano pelas mulheres, a proporção de crianças e jovens nos cultos, a introdução de certos rituais. O dinamismo demonstrado pelos grupos organizados dentro das igrejas (grupo de mulheres, de jovens, de homens) em situações de óbito ou casamento, por exemplo, indicam o envolvimento (e o respeito) da igreja nas situações em que a autoridade localiza-se dentro das famílias.

Tomemos aqui como exemplo o uso das línguas nos cultos. A escolha do português como língua principal de culto, para além da necessidade de atingir uma audiência plural e multiétnica, como normalmente é justificado, indica também uma vontade da própria igreja de assumir um ponto de vista mais "nacional", na medida em que, em Angola, e especialmente em Luanda, o uso da língua portuguesa se faz hegemônico. Este é o caso da igreja católica.

Já a predominância do lingala nos cultos, mais do que conformar-se a uma assistência de maioria regressada ou congolesa, pode sugerir uma vontade ou uma inclinação para um culto mais fechado, voltado para um grupo que encontra nas igrejas, principalmente as proféticas, um espaço privilegiado de reprodução de um modo de vida específico, tendência maior que a de assimilação.

O uso do kikongo, quase sempre mesclado com o português, aponta para um espaço de valorização cultural fincado na tradição bakongo e voltado para um tipo de público bastante sensível à manutenção do kikongo como língua de grupo, de valorização da tradição e de suas instituições. O uso alternado com o português indica a dupla necessidade de integração e atenção ao espaço nacional, numa forma cadenciada que aponta para a construção de uma identidade que quer ser ao mesmo tempo nacional e étnica.

Há uma variação enorme no uso das diferentes línguas nas diferentes igrejas nos diferentes momentos de culto. Pode-se pensar em quatro

${ }^{24}$ Língua materna dos bakongo

25 O lingala é a língua mais acionada na RDC, na região em torno da capital, Kinshasa, que se expande para outras regiões do Congo e da África Austral. É a língua do exército e, sobretudo, da disseminada música congolesa. 
espaços nos cultos, nos quais o uso das línguas é demarcado. O primeiro espaço é o da pregação, no qual há um discurso direto da autoridade religiosa, pastor ou padre, para os fiéis. Há uma interação relativa entre fiéis e pastor, mas com o controle do último. O segundo espaço é o da oração (e dos hinos), estabelecendo a comunicação entre o corpo de fiéis (incluindo autoridades e assistência) com Deus. São situações caracterizadas pela solenidade e pela contrição. O terceiro espaço é o das leituras bíblicas, que pode ser feita pelo pastor, padre, mas também outros ministrantes. É quando Deus e seus mediadores (apóstolos, profetas) se comunicam com seus fiéis via palavra escrita (indicado pela expressão "vamos ouvir a Palavra de Deus"). O ultimo espaço é o dos cânticos, canções e músicas de empolgação, no qual há uma comunicação mais relaxada entre fiéis - bandas, corais e o público assistente. Neste espaço, podemos também inserir os avisos comunitários e recomendações, que dizem respeito à comunidade religiosa e mais ampla, bem como testemunhos feitos por fiéis (especialmente nas igrejas pentecostais). Em muitos cultos, esse espaço é o que toma mais tempo - e onde há maior variação de línguas.

No caso do culto da IEBA, a pregação é feita em português, com tradução consecutiva para o kikongo. As orações são feitas quase sempre em kikongo, indicando, o lugar ritual e quase sagrado ocupado pela língua materna. As leituras bíblicas são feitas em português e em kikongo, consecutivamente. Os cânticos são cantados em várias línguas: lingala, kikongo, francês, embora pouco em português.

Um inventário das variações encontradas nos cultos das várias igrejas seria excessivo aqui, mas é relativamente frequente a situação de maior variedade linguística nos cânticos, bilinguismo nas leituras e na pregação e monolinguismo nas orações. Cabe reiterar que esta ordenação não atende apenas a uma situação pragmática de adequação ao público ou de minimização do tempo ou do esforço dispensado nas traduções. Quero dizer que, mais que uma adequação à composição da congregação, as línguas utilizadas são fruto de uma escolha que, além de levar em conta as características e necessidades desta audiência e a trajetória do pastor ou ministrante, indica principalmente o lugar e o papel que cada denominação e cada comunidade religiosa pretendem ocupar e desempenhar dentro do grupo e fora dele. 
Portanto, à dimensão "universal" ou nacional da igreja católica, expressa por sua liturgia e sermão efetuados em português, mas com cânticos em kikongo e outras línguas, vamos contrapondo igrejas de tradição missionária, como a batista, que organiza seu culto buscando um equilíbrio entre o kikongo e o português, até igrejas, como a maioria das proféticas/pentecostais, que fazem seu culto quase que exclusivamente em lingala ou, como a Igreja Universal do Reino de Deus, de origem brasileira, exclusivamente em português. A Igreja Tocoísta, que prima por ser uma igreja especificamente angolana, dá um espaço interessante às diversas línguas angolanas, especialmente nos cânticos, mas não só, que não pertencem necessariamente ao público presente no culto em questão, como o chokwe e o umbundo. ${ }^{26}$ É como se dissesse "nós somos 'a' igreja angolana propriamente dita" - e dizer angolano é dizer através de todas as suas línguas e expressões. A pregação do culto tocoísta, assistida no bairro Palanca, foi feita em português, kikongo e kimbundo, indicando uma afirmação de "angolanidade" baseada no uso das diversas línguas, independentemente da composição étnica dos fiéis, e não no uso quase exclusivo do português.

Se as comunidades e lideranças religiosas costuram meios diferentes de associar identidade étnica e nacional a partir da manipulação do uso das línguas, outros sinais expressos pelas comunidades de fé, durante os cultos, indicam outras formas de relacionar a vivência religiosa e a participação das igrejas na vida comunitária e nas redes de parentesco. Há também alguns indícios de como estas "irmandades" vivenciam certos aspectos da cultura kongo, da influência da cultura congolesa, recebida em Kinshasa, e os aportes da cultura "angolana" veiculados pela sociedade envolvente de Luanda.

As roupas exibidas pelas mulheres nos cultos são um sinal interessante de como se compõe o público das diferentes igrejas. O uso de panos e amarrados comuns ao vestuário kongo, e/ou determinadas roupas tidas como tipicamente congolesas (vestidos de mangas bufantes ou conjuntos de blusas, saias e torços, determinados tipos de adereços),

${ }^{26}$ Línguas respectivamente do leste e do centro de Angola, esta, do maior grupo étnico angolano, os ovimbundu. 
associado ao uso de maquiagem, tipos de penteados, uso de lenços etc., indicam a composição da audiência bakongo angolana, se tem maior ou menor presença de regressados ou de congoleses, ou inclui população mais "luandizada" (como é percebida no uso de jeans e roupas mais "ocidentais"). Essa composição de vestimentas não é aleatória e se constrói a partir também de estímulos e controles vindos de dentro e de fora do grupo (como o caso de pastores e lideranças religiosas que reclamam do tipo de roupa utilizado pelas jovens, por exemplo, e a influência do modo de vestir da capital). O fato é que uma presença maior de mulheres adultas vestidas de panos e a maior frequência de crianças às costas apontam para um tipo de comunidade de igreja que dá muito valor aos aspectos mais tradicionais da família kongo radicada em Luanda, conferindo um relacionamento bastante íntimo entre lideranças religiosas e tradições ancoradas na família. A dedicação de determinadas igrejas à educação e evangelização de crianças e adolescentes (caso principalmente das igrejas Batista, Exército da Salvação, Kimbanguista, Católica) demonstra um investimento antigo na relação entre igreja e família que se traduz pela adesão de tipo familiar que já apontamos acima.

Nesse sentido, podemos ver como as igrejas proféticas e pentecostais, cujos fiéis aderem em busca da experiência extática de contato direto com o divino, das promessas de cura e de proteção contra a feitiçaria, prescindem de um tipo de organização baseada na adesão familiar. E assim, estabelecem estratégias de captação destes fiéis nas bordas da clientela das igrejas de adesão tradicional/familiar, muitas vezes rompendo com lealdades baseadas no parentesco e nos sistemas culturais engendrados por estas redes. Assistindo diversos cultos em igrejas proféticas e/ou pentecostais, percebemos pouca presença de crianças e idosos e que pouco se fazia menção a eventos e festividades comunitárias que não dissessem respeito especificamente à comunidade de fiéis. $\mathrm{O}$ uso quase exclusivo do lingala ou do português (caso da Igreja Universal do Reino de Deus - IURD) indicava pouca inclinação ao estímulo de identidades culturais mais articuladas - seja com o grupo bakongo enquanto tal, seja com outros grupos étnicos e nacional. 


\section{Formas de adesão religiosa e modelos de igrejas}

Se avançarmos na ideia de que as filiações às diferentes igrejas atendem a uma divisão entre uma adesão de tipo familiar e uma adesão "pulverizada", ou seja, não relacionada à inserção familiar e, talvez, de camadas do grupo menos enquadradas do ponto de vista do parentesco (mais jovens, mais pobres, recém-chegados do Congo ou do norte de Angola que não contam com rede estável de apoio familiar), podemos pensar, seguindo a abordagem de MacGaffey na sua análise sobre igrejas proféticas na região do Baixo Congo (RDC), ${ }^{27}$ que esta divisão reflete dois grupos sociais, distinguidos entre grupos organizados em torno das instituições familiares e grupos marginalizados, de diversas formas, desta estrutura.

MacGaffey indica que a adesão às igrejas proféticas se dá predominantemente entre indivíduos e grupos considerados "perdedores" dos dois setores, chamados "costumeiro" e "burocrático", que compõem o sistema que ele chama de "sociedade plural", seja ela colonial ou póscolonial. As pessoas que estão tanto à margem do sistema tradicional (ou seja, à margem do grupo de poder e prestígio que é adquirido pela posição no grupo de parentesco ou nas linhagens mais prestigiadas), quanto à margem do sistema burocrático (colonial ou do aparelho de Estado, ou fora do acesso aos bens de consumo e simbólicos propiciados pelo acesso ao sistema ocidentalizado) seriam passíveis de serem incorporadas nos grupos religiosos de tipo profético, de organização menos hierarquizada, cujo acesso à divindade se dá por via mais imediata (êxtase, possessão, cura divina, "profetização").

No caso das adesões dos bakongo às diversas denominações em Angola, percebi forte ressonância com as observações de MacGaffey. As igrejas mais antigas (as mais estabelecidas, de organização mais hierarquizada e centralizada) são aquelas nas quais os grupos familiares perfazem a maior assistência, com uma presença expressiva de homens (e mulheres) mais velhos. Os sinais acima apontados, que indicam o tipo de composição da "clientela" das diferentes igrejas e sua aproxi-

27 Wyatt MacGaffey, Modern Kongo Prophets: Religion in a Plural Society, Bloomington: Indiana University Press, 1983. 
mação com as instituições familiares - língua, tipo de roupa, presença de crianças etc. - confirmam a distinção sugerida por MacGaffey entre um modelo de igreja mais "universal" ou missionário (plurilíngues, hierárquicas, com ênfase na liturgia e na leitura da Bíblia) e as igrejas de tipo "espiritual" (monolíngues, com organização pulverizada de baixa hierarquia e centradas na relação entre pastor/profeta carismático e fiéis, menos hierárquicas, que priorizam os rituais extáticos e de possessão voltadas para a cura e resistentes à burocratização e liturgias rotinizadas). ${ }^{28}$ Estas últimas atendem a uma clientela de indivíduos deslocados de suas famílias, principalmente mais jovem e mais pobre.

Nessa distinção, a trajetória da Igreja Kimbanguista torna-se interessante, pois, com origem no movimento messiânico ou profético mais bem sucedido da África Central, foi a igreja referida por MacGaffey para demonstrar a sua tese da adesão dos "perdedores" do "sistema plural" aos movimentos proféticos. Atualmente, a Igreja Kimbanguista é uma das mais importantes igrejas africanas: bem estruturada, altamente hierarquizada e burocratizada, na qual as manifestações "espirituais" (possessão, glossolalia, profetizações, cura divina) vêm perdendo espaço para uma organização mais controlada e com uma liturgia mais previsível. ${ }^{29}$ Hoje, a composição dos fiéis da Igreja Kimbanguista é de tipo "familiar", tal como a Católica, Exército da Salvação, Batista. A Igreja Tocoísta é outro exemplo de igreja herdeira dos movimentos proféticos que se institucionalizou.

A Igreja Batista e seus desmembramentos me pareceu constituir um ponto de observação interessante para explorar algumas questões em torno da adesão religiosa, seus critérios e dinâmica, e das relações de afastamento e aproximação da esfera religiosa institucional com a esfera familiar e as relações de parentesco.

A IEBA é uma igreja que se encaixa bem dentro do modelo chamado de "universal" ou "missionário", não apenas pela sua história, mas também pelo nível de hierarquização e burocratização, com um corpo de bispos, pastores, evangelistas, diáconos, organizada em con-

28 MacGaffey, Modern Kongo Prophets, p. 68.

29 MacGaffey, Modern Kongo Prophets, p.118. 
selhos, comissões e assembleias. A formação de vários pastores é feita no exterior, seja no Congo, na Inglaterra (com a colaboração da antiga matriz) ou no Brasil. A admissão do fiel na igreja depende de ele atender a pré-requisitos, sendo necessário aguardar um período até ser admitido como membro efetivo.

A União Evangélica Baptista de Angola (UEBA), por sua vez, é uma igreja de bem menor expressão e com menos recursos, em comparação com a IEBA, tendo sido fundada em 1991, em Angola, por um antigo pastor da IEBA. ${ }^{30}$ Com sede no próprio bairro Palanca, conta com alguns templos em Luanda e outras províncias, principalmente no Uíge. Embora formalmente tenha uma estrutura burocrática, com conselho e administração, na prática as decisões são muito centradas no pastor. A forma de adesão de seus membros se deu, prioritariamente, nas bordas da IEBA, aproveitando-se da resistência de alguns membros a aceitar a rigidez disciplinar e burocrática da última, e do carisma do pastor, capaz de "arrebanhar" seguidores na sua própria região de origem, como veremos.

O culto dominical da UEBA segue de perto aquele visto na IEBA, alternando cânticos, pregação e avisos comunitários, e com o mesmo tipo de organização interna de fiéis. Todavia, segundo alguns destes fiéis, a UEBA estaria aproximando o seu culto de um tipo mais pentecostal, o que não foi percebido nos domingos, mas sim nos encontros das mulheres, às quartas-feiras, nos quais acontecem, eventualmente, alguns rituais extáticos. O tipo de leitura bíblica feita nestes encontros parece também confirmar este fenômeno de pentecostalização. O acompanhamento contínuo do "culto das mamãs" da UEBA no Palanca, bem como a visita a alguns encontros de mulheres da IEBA no bairro do Petroangol, teve como objetivo entender a dinâmica entre comunidade de fiéis, redes de parentesco e vizinhança.

As igrejas batistas me pareceram as mais interessantes como ponto de partida para observar o entrelaçamento das esferas familiar e religiosa, já que pude notar ali uma maior aproximação, em comparação com as igrejas pentecostais. Estas parecem estabelecer um rompimento mais

30 Viegas, "Angola e as religiões", p. 301. 
nítido, provocado por um fechamento maior da comunidade religiosa em torno de si mesma. Observar as igrejas a partir das suas relações de aproximação e afastamento com a base familiar e a comunidade de vizinhança é uma maneira de compreender as formas de adesão e trânsito religioso dos bakongo do bairro Palanca e de Luanda. Do mesmo modo, pode-se compreender como as cada vez mais numerosas igrejas pentecostais vão captando seus fiéis e como a esfera familiar/tradicional e a religiosa se interferem e se complementam.

Algumas diferenças se apresentam entre duas igrejas de mesma matriz, no caso a Batista, num mesmo tipo de culto, o "culto das mamãs". Além de cultos mais dinâmicos na UEBA, nos quais eventualmente aconteciam situações de êxtase e glossolalia, pude perceber mais autonomia das mulheres dessa igreja para organizar seus próprios encontros do que entre as mulheres da IEBA (o que foi observado nos encontros da paróquia da IEBA do bairro do Petroangol). Na UEBA as mulheres cantavam e tocavam instrumentos, dirigiam o culto e convidavam, elas mesmas, os pastores que iam fazer pregação, diferente das senhoras da IEBA, muito dependentes da hierarquia e do comando masculino personalizado no pastor. Na UEBA, o lingala era bastante utilizado tanto nos cultos das quartas-feiras, traduzido quase sempre para o português, bem como nos cultos dominicais, ao contrário da IEBA, onde se repete invariavelmente o padrão português - kikongo, ainda que a maioria das mulheres falassem preferencialmente o lingala fora da situação de culto.

Estas diferenças dentro do campo das igrejas batistas indicam uma inclinação da igreja dissidente para um tipo de organização e dinâmica de culto que se aproxima da estrutura profética/pentecostal - igreja menos hierarquizada, autonomia das mulheres, cultos extáticos, uso do lingala, praticamente sem referência ao kikongo. Considerando estas diferenças e levando em conta a trajetória da Igreja Kimbanguista, percebemos que não é possível, a partir apenas da denominação exterior comumente dada às igrejas - protestantes missionárias, pentecostais, proféticas, messiânicas ou igrejas independentes - depreender sua organização e dinâmica interna. Também as formas pelas quais os seus fiéis aderem e transitam entre uma e outra, supostamente das protestantes históricas e católicas para as pentecostais/proféticas, deve ser mais 
bem matizadas. Deve-se observar especialmente como as igrejas estão relacionadas entre si e o lugar que cada uma delas ocupa dentro do que chamaríamos campo religioso angolano ou luandense e de acordo também com a sua história.

A distinção feita entre modelos missionário (universal) e profético/pentecostal (sectário) deixa também de lado outra possibilidade de leitura que diz respeito ao fenômeno da proliferação das igrejas, seja no caso das igrejas chamadas proféticas ou espirituais, mas principalmente no caso dos desmembramentos entre as igrejas mais antigas, como as protestantes missionárias e a Igreja Tocoísta (a Igreja Kimbanguista não havia sofrido esta situação de desmembramentos até o período de observação). Pensar em formas e modelos de adesão às diferentes igrejas com base apenas no modelo da igreja e na posição social do adepto não dá conta da lógica que opera nas múltiplas cisões ocorridas dentro das várias igrejas e no trânsito contínuo de fiéis entre uma e outra igreja.

Sugiro assim nos voltarmos mais uma vez para o caso específico das igrejas batistas, situadas no modelo "universal", para encontrarmos pistas para compreender este fenômeno.

\section{Adesão e trânsito religioso: o "poder local"}

Em visita aos cultos das mamãs da IEBA, no bairro do Petroangol (outro bairro da periferia de Luanda com forte presença de bakongo/regressados), ouvi de algumas senhoras da direção que a UEBA era uma igreja de pessoas de Beu e de Kimbele, localidades do município de Maquela do Zombo, Uíge, norte de Angola, área de origem do pastor fundador da UEBA. Embora os membros desta rejeitassem firmemente esta categorização, pude observar que vários dos membros da igreja que estão em cargos de maior peso são de fato desta região.

Dois relatos que obtive destes integrantes da UEBA explicam como eles ingressaram na igreja. Os dois eram membros da IEBA e se integraram a UEBA quando chegaram a Luanda, vindos do Uíge, e antes, do Congo/Zaire. Um deles havia recebido uma punição da IEBA por ter se envolvido com uma moça sem contrair matrimônio. Não quis aceitar o prazo de punição e o tempo longo fora dos quadros da igreja 
para sua posterior reintegração e, assim, mudou-se para a UEBA. O outro relatou a dificuldade de transferir sua documentação da paróquia do Uíge para Luanda e, não querendo perder sua condição de membro efetivo que o obrigaria a cumprir de novo uma série de requisitos, preferiu se juntar a UEBA. Cabe ressaltar que ele tinha relações de parentesco com o pastor, pai do seu cunhado (marido da irmã).

Estes relatos confirmam outras conversas que indicaram a flexibilidade da UEBA em receber fiéis com qualquer dificuldade de se adequar à rigidez e à disciplina que seriam impostas pela direção da IEBA. Outras igrejas menores vêm "roubando" aderentes das igrejas mais "ortodoxas" e a IEBA aparece aqui como uma das principais igrejas "doadoras" de fiéis.

Independente da motivação para a saída de uma determinada igreja, a adesão parece obedecer aos imperativos de solidariedade local, ou seja, pode ocorrer entre fiéis de mesma origem - e neste caso, local de origem pode alcançar a escala da localidade (Beu ou Kimbele), do município (Maquela do Zombo) ou da província (Uíge) -, como de local de residência próximos (mesmo bairro ou área do bairro) como também de parentesco por aliança. Estas variantes de localidade e parentesco reeditadas em Luanda aparecem associadas quando observamos a composição de pequenas igrejas. Verifica-se assim uma relação complexa e diversificada entre os grupos religiosos, familiares, de vizinhança, de origem, e outras alianças. $\mathrm{O}$ trânsito religioso produz também impactos variados dentro das famílias, sobretudo dentre aquelas que têm uma adesão antiga às igrejas católica e batista, as quais vêm perdendo seus adeptos para as igrejas menores e mais recentes. ${ }^{31}$

As próprias famílias também adotam posturas diferentes quanto às exigências das diversas igrejas, ou harmonizando as distintas lealdades de cada membro da família, ou adotando uma postura de menor tolerância quanto ao trânsito religioso de seus parentes. Comumente, as esposas costumam migrar para a igreja dos maridos ao casarem-se, sem

${ }^{31} \mathrm{O}$ trânsito de fiéis implica também no retorno destes às igrejas originais, embora não tenha sido possível fazer um acompanhamento passo a passo do trânsito religioso. Apenas tive notícia de retorno de fiéis às igrejas anteriores, mas desconheço o impacto deste retorno. 
causar grande desagrado aos seus parentes. Por vezes, há desavenças familiares devido a filiações religiosas divergentes entre cônjuges e entre pais e filhos.

Porém, outro fator que chama atenção nestes constantes desmembramentos nas igrejas é a semelhança deste fenômeno com a estrutura social bakongo. O desmembramento de igrejas parece encontrar certo paralelismo com a segmentação dos grupos de parentesco, que é uma característica reiterada da organização social kongo. As fissuras constantes nas linhagens originalmente provocavam a migração em busca de novas terras e a consolidação de novos poderes, de outra forma incapazes de ascender na estrutura hierárquica kongo, que concentra o poder na mão dos mais velhos, dos primogênitos e das linhagens centrais. A emergência de novas lideranças parece semelhante à estrutura segmentar do parentesco bakongo, que é segmentar justamente pela sua feição hierárquica, geradora de tensões dentro do grupo. Situado no contexto urbano, no qual a busca por poder não pode mais estar associada à conquista territorial, é possível que as igrejas, inseridas nesta rede de contínuas fragmentações, possam ser pensadas também como uma reposição desta estrutura original de parentesco.

Poderíamos assim traçar um paralelo ou equivalência entre igrejas menores que saem de igrejas maiores e as subdivisões de linhagens na estrutura de parentesco. Esta reacomodação dá lugar não apenas para lideranças - os pastores - controlarem novos "rebanhos", mas também para chefes de famílias menores, que assumem cargos nas pequenas estruturas de comando destas igrejas, terem um espaço de influência e poder que seria impossível exercerem tanto nas igrejas maiores, como em suas próprias famílias extensas. Repõe-se assim, no âmbito das igrejas, o reincidente conflito de gerações, que opõe não apenas os mais velhos chefes de linhagem aos mais jovens (solteiros), mas, neste caso, homens que comandam famílias nucleares - ou seja, a unidade doméstica, que ganhou maior importância no contexto urbano e nacional, de poder paterno - mas que têm pouco espaço nas decisões familiares mais alargadas. Possivelmente, estes homens "pais de famílias nucleares" se apropriam do prestígio obtido com as igrejas para se recolocarem melhor diante da rede de parentesco e mais amplamente no âmbito das 
relações sociais mais alargadas. Homens bem posicionados nas relações familiares - possuindo família extensa - são fiéis bem vindos à estrutura das igrejas.

MacGaffey, na análise que faz sobre o movimento profético no Congo após sua independência (1961), aponta para o fato de as igrejas ocuparem hoje o lugar dos antigos cultos territoriais, desempenhados pelos antigos ngangas, os sacerdotes locais. ${ }^{32}$ Os padres, durante a evangelização do reino do Kongo, foram considerados pela cosmologia local como ngangas. MacGaffey defende que os profetas atuais (ou os líderes de igrejas pentecostais, também chamados por seus seguidores de profetas) substituíram os antigos ngangas, assumindo um papel de chefia políticoreligiosa, num poder transversal àquele exercido pelas autoridades de parentesco. A autoridade político-religiosa se exerce assim localmente, em contraposição às chefias de linhagem que exercem seu poder de forma não-local, posto que a matrilinhagem se encontre dispersa no espaço. Pode-se considerar, portanto, as igrejas, no contexto de Luanda, como uma estrutura de sociabilidade local transversal à de parentesco.

Retomando a discussão sobre a transmissão via paterna de poder territorial e espiritual, vemos como esta relação é homóloga ao processo de fragmentação das igrejas, evidenciada pelo poder dos líderes religiosos exercido localmente. Seguindo este argumento, da mesma forma que a fragmentação de linhagens no sistema kongo era regulada através de uma linguagem de parentesco (relação tata-mwana), pode-se afirmar que a estrutura transversal de sociabilidade e poder efetivada pelas igrejas e pelo sistema pastor - lideranças religiosas - fiéis, mantém relações de continuidade com as relações de parentesco efetivadas pela linhagem (kanda). Sugiro assim, que o padrão de multiplicação das igrejas entre os bakongo obedece, em parte, a padrões de fragmentação de grupos de parentesco já descritas na bibliografia sobre o grupo. ${ }^{33}$ Portanto, a sociabilidade e organizações baseadas nas igrejas e aquelas baseadas no parentesco possuem uma relação complexa e interdependente, e não de sucessão.

32 MacGaffey, Modern Kongo Prophets, p. 62

${ }^{33}$ Balandier, Sociologie actuelle; MacGaffey, Religion and Society; Gonçalves, Reestruturação do poder político. 


\section{Conclusão}

As questões aqui discutidas, de transformações sociais e culturais, que em Angola foram agudizadas por uma guerra contínua, dizem respeito a um processo global de mudanças de padrões culturais dados pela urbanização acelerada, pela alteração das formas de sociabilidade através da integração ao conjunto nacional. Essas mudanças tocam de perto os processos identitários e, em consequência disto, a reformulação de demandas políticas num contexto ainda autoritário, apesar da paz recentemente alcançada.

Reitero aqui que o modo como os grupos sociais pensam e reconstroem seus percursos históricos, vividos sob o signo da mudança e da necessidade de inserção nestes contextos difíceis, opera especialmente com a composição de elementos e a partir de determinados sistemas de pensamento e ação que "façam sentido" e que lhes permitam tentar controlar estas transformações e seu lugar nelas.

Considera-se que uma das consequências promovidas pela urbanização aguda, no caso angolano, mas também em outras situações africanas, seria o enfraquecimento dos laços de parentesco e do seu papel como principal ordenador social, em prol de outras formas de sociabilidade, autoridade e legitimidade que vêm emergindo do processo de construção nacional e do espraiamento da lógica de mercado. Este trabalho procurou distinguir-se de um senso comum que supõe que laços de parentesco fragilizados neste processo de urbanização são substituídos por outras relações, como religiosas, de vizinhança, ou por uma etnicidade urbana "reinventada". Uma das perspectivas deste trabalho é que os laços de parentesco, apesar de relativamente enfraquecidos no contexto urbano, são somados e superpostos a outras formas de organização social. Esta nova configuração, por sua vez, faz com que os laços de família e parentesco sejam também recriados, garantindo sua permanência e pertinência como instância fundamental nas redes sociais dos bakongo em Angola.

Texto apresentado em 25 de julho de 2011 e aceito em 10 de outubro de 2011 


\section{Resumo}

Este artigo tem como objetivo discutir as relações entre religião e parentesco entre os bakongo, um dos principais grupos étnicos de Angola. Explora as formas específicas pelas quais este grupo reorganiza-se internamente no contexto de Luanda desde a independência, a partir da entrada de importantes contingentes antes exilados no então Zaire, atual República Democrática do Congo (RDC) em Luanda. Procura-se demonstrar como e porque a religião vem sendo a principal instituição mediadora que integra diferentes instâncias tais como recomposição de redes de sociabilidade e parentesco num contexto urbano, veiculação de identidades étnica e nacional, dando sentido tanto às transformações ocorridas quanto aos processos de continuidade na história recente dos bakongo em Luanda. Esta demonstração se fará através da análise do pentecostalismo em Angola tomando como ponto de observação os bairros periféricos de Luanda de grande concentração bakongo.

Palavras-Chave: Angola - bakongo - parentesco - religião - igrejas africanas

\section{Abstract}

This article discusses the relationship between religion and kinship among the Bakongo, one of Angola's main ethnic groups. It explores the specific forms in which this group reorganizes itself internally in the context of Angola's capital, Luanda, since the country's independence when many of them returned from exile in Zaire (presently the Democratic Republic of Congo). It shows how and why religion is the main mediating institution that integrates various levels remaking sociability and kinship networks in an urban context, bringing forth national end ethnic identities - and gives meaning both to transformations and to continuities in the Bakongo's recent history. The demonstration will be made by means of the analysis of Pentecostalism in Angola, as observed in neighborhoods where the Bakongo are concentrated.

Keywords: Angola - Bakongo - Kinship - religion - African churches 